University of Nebraska - Lincoln

DigitalCommons@University of Nebraska - Lincoln

2011

\title{
A sticky situation: Solifugids (Arachnida, Solifugae) use adhesive organs on their pedipalps for prey capture
}

Rodrigo H. Willemart

University of Nebraska-Lincoln, willemart@usp.br

Roger D. Santer

University of Nebraska-Lincoln, rds5@aber.ac.uk

Andrew J. Spence

Royal Veterinary College, University of London, aspence@rvc.ac.uk

Eileen Hebets

University of Nebraska - Lincoln, ehebets2@unl.edu

Follow this and additional works at: https://digitalcommons.unl.edu/bioscihebets

Part of the Behavior and Ethology Commons

Willemart, Rodrigo H.; Santer, Roger D.; Spence, Andrew J.; and Hebets, Eileen, "A sticky situation: Solifugids (Arachnida, Solifugae) use adhesive organs on their pedipalps for prey capture" (2011). Eileen Hebets Publications. 39.

https://digitalcommons.unl.edu/bioscihebets/39

This Article is brought to you for free and open access by the Papers in the Biological Sciences at DigitalCommons@University of Nebraska - Lincoln. It has been accepted for inclusion in Eileen Hebets Publications by an authorized administrator of DigitalCommons@University of Nebraska - Lincoln. 
Published in Journal of Ethology 29 (2011), pp. 177-180; doi: 10.1007/s10164-010-0222-4

Copyright $(92010$ Japan Ethological Society and Springer. Used by permission.

Submitted February 23, 2010; accepted May 17, 2010; published online June 12, 2010

Supplementary material for this article is included following the "References."

\title{
A sticky situation: Solifugids (Arachnida, Solifugae) use adhesive organs on their pedipalps for prey capture
}

\author{
Rodrigo H. Willemart, ${ }^{1}$ Roger D. Santer, ${ }^{1}$ Andrew J. Spence, ${ }^{2}$ and Eileen A. Hebets ${ }^{1}$ \\ 1. School of Biological Sciences, University of Nebraska-Lincoln, Lincoln, NE, USA \\ 2. Structure and Motion Laboratory, Royal Veterinary College, University of London, Hertfordshire, UK
}

\begin{abstract}
Corresponding author - Rodrigo H. Willemart; Present address: Escola de Artes Ciências e Humanidades, Universidade de São Paulo, Rua Arlindo Béttio, 1000, Ermelino Matarazzo, São Paulo, 03828-000, Brazil; email willemart@usp.br

Present address for Roger D. Santer - Department of Life Sciences, Schrodinger Building, University of Limerick, Limerick, Ireland
\end{abstract}

\begin{abstract}
Solifugids (Arachnida, Solifugae) have unique evertable adhesive organs on the tips of their pedipalps, named 'suctorial' or 'palpal' organs. Previous studies have shown that these organs enable solifugids to climb smooth glass-like surfaces and have hypothesized that these structures facilitate prey capture. Here, we use high-speed videography to demonstrate that the suctorial organs of Eremochelis bilobatus are its primary means of capturing insect prey. We also present calculations of the adhesive pressure exerted by these suctorial organs during real prey capture events.
\end{abstract}

Keywords: solifuge, adhesion, foraging, suctorial organ, palpal organ

\section{Introduction}

The diverse array of animal adhesive organs are fascinating subjects for study, not least because these intricate and evolutionarily-honed structures can inspire the design of effective man-made adhesives (Lee et al. 2008; Schubert et al. 2008). Among arthropods, adhesive organs are common (Betz and Kölsch 2004; Clemente and Federle 2008), and most play important roles in locomotion, prey capture, or both (e.g., Rovner 1980; Kesel et al. 2003; Betz and Kölsch 2004).
Certainly enigmatic among arthropod adhesive organs are the 'suctorial organs' of solifugids (arachnids commonly called camel spiders or sun scorpions). Unlike other arachnids, solifugids possess an evertable membranous organ on the tip of each pedipalp (Cushing et al. 2005; Klann et al. 2008) (Figure 1). These organs allow solifugids to climb smooth surfaces (e.g., Cushing et al. 2005), and convey water to their mouthparts for drinking (Savory 1964). Anecdotal observations indicate that these organs are also used in prey capture: solifugids directly strike at prey with their chelicerae or grasp them with their suctorial organs, depending on factors such as prey size and sclerotization, and solifugid size and species-specific behavior (e.g., Muma 1966; Punzo 1998). However, these observations have remained anecdotal because the rapidity of prey capture makes detailed observation difficult. Equally problematic, although outside the scope of this study, is understanding the adhesive mechanism involved: although named for a presumed suctorial function, recent morphological studies suggest that surface features, and the lack of glandular openings, indicate that dry adhesive mechanisms, for example van der Waals forces, predominate (Cushing et al. 2005; Klann et al. 2008). 


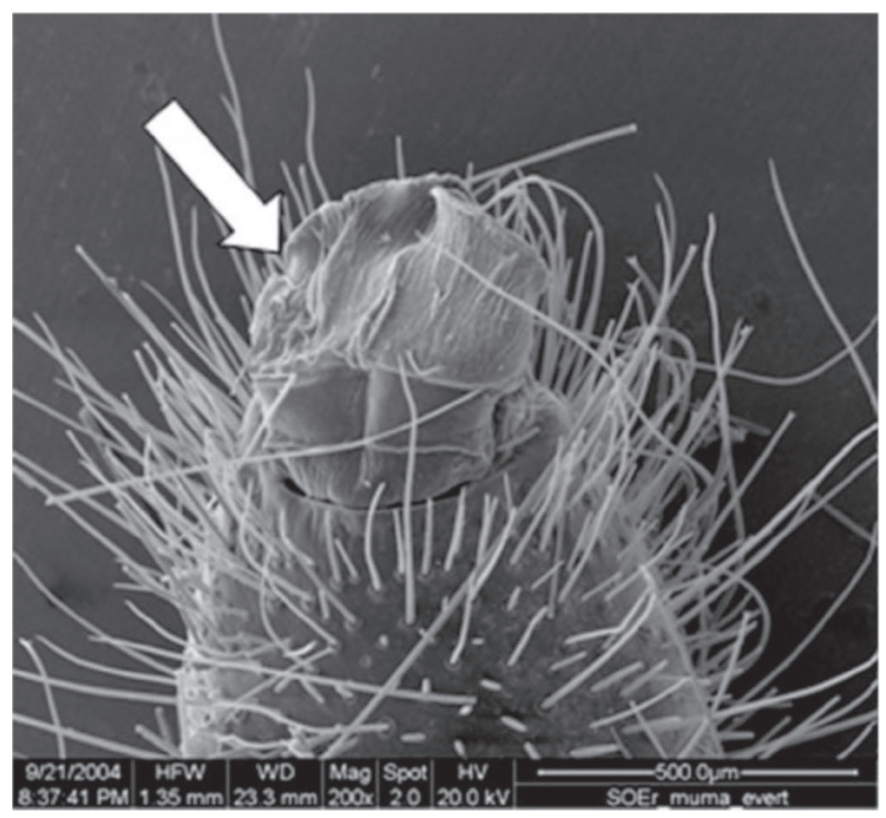

Figure 1. Tip of the pedipalp of Eremorhax mumai Brookhart, 1972, showing the everted suctorial organ (arrow), ventral view (by P. Cushing).

Here, we use high-speed videography to substantiate previous impressions that the suctorial organs of Eremochelis bilobatus are its primary means of capturing insect prey of various sizes. We also make tentative calculations of the adhesive pressure developed by these organs during prey capture.

\section{Materials and methods}

Two adult male and one adult female Eremochelis bilobatus (family Eremobatidae, subfamily Therobatinae) were collected from Crow Valley Recreation Area, Pawnee National Grassland, Colorado, USA ( $40^{\circ} 38.684^{\prime} \mathrm{N}$, $104^{\circ} 20.647^{\prime} \mathrm{W}$, elevation 1,479 m) in June 2007.

Solifugids were filmed capturing laboratory-reared crickets of various sizes (Acheta domestica, Gryllus lineaticeps, and Gryllus firmus), which comprised the solifugids' normal diet in the laboratory. Crickets occur in the Pawnee National Grassland and are often the most consumed prey item in field studies of solifugids (Punzo 1997, 1998). Films were recorded using a Fastcam 1024PCI high-speed digital camera (Photron USA, San Diego, CA, USA) at $500 \mathrm{fps}$. Prey capture was filmed from the side with the animals contained within an arena $130 \mathrm{~mm}$ wide $\times 137 \mathrm{~mm}$ high $\times 35 \mathrm{~mm}$ deep. The narrow depth of the arena limited movement in the $z$-plane, allowing 2-dimensional ( $x, y$ plane) analysis of movement. In total, we successfully filmed 27 prey capture sequences.

\section{Results}

High-speed videos clearly showed that E. bilobatus used its pedipalps as its primary means of prey capture. In all 27 prey capture events, a solifugid reacted behaviorally to a walking cricket only after contact, and crickets were always attacked first with the tip of the pedipalp (bearing the suctorial organ), never with the chelicerae. A single pedipalp was characteristically used for prey capture. Upon contact, the prey became immediately 'stuck', adhering to the suctorial organ (Figure 2). Solifugids were able to bring airborne jumping crickets to the ground with their suctorial organs, demonstrating strong adhesive forces (supplementary materials). In all observed instances of prey capture, the suctorial organs were the primary means of capture. Solifugids were also observed to use their suctorial organs to grasp the experimenter's forceps prior to an attack with their chelicerae, potentially indicating an additional defensive function for these suctorial organs.

\section{Discussion}

Using high speed videography, we were able to verify a prey capture function for the solifugid suctorial organs. Observations of our 27 prey capture sequences clearly corroborate the intuition of previous researchers regarding the foraging function of these specialized organs. Despite their previously demonstrated capacity to function in climbing smooth surfaces (Cushing et al. 2005), the natural history of most solifugids calls into question the natural relevance of such behavior. Solifugids are typically found in dry, arid habitats, under rocks or other debris, in crevices, or in burrows (Punzo 1998), meaning that they should rarely have to climb smooth, vertical surfaces. In cases where such surfaces do occur (such as smooth leaves), then the suctorial organs could also help in locomotion.

Arachnids are predators and many, if not most, members of this group utilize their pedipalps during prey capture and manipulation. The pedipalps of many arachnid groups are modified into pincer-like or raptorial appendages specialized for prey capture (e.g., amblypygids, uropygids, schizomids, some opilionids, scorpions, and pseudoscorpions; see Beccaloni 2009). Some groups also possess pincer-like modifications of their chelicerae (e.g., opilionids, scorpions and pseudoscorpions; see Beccaloni 2009). Previously, spiders were confirmed to use adhesive organs for prey capture, by means of adhesive setae on the legs (Rovner 1980), and a few species of harvestmen from the northern hemisphere were known to use sticky glandular setae on the pedipalps to capture prey (e.g., Gruber 1970, 1974). Solifugids are now the third arachnid group substantiated 
Figure 2. Example frames from a 500 frames/s recording of E. bilobatus capturing a jumping cricket using the suctorial organ on the tip of the pedipalp: The unalarmed cricket approaches and touches the solifugid (a), which backs up (b), raises its pedipalps (c) and approaches the cricket with the chelicerae open (d). One pedipalp makes contact with an antenna of the prey, which pulls back (e) and jumps (f). Still held by the tip of the solifugid's pedipalp, the cricket kicks (g) and jumps again in unsuccessful attempts to escape $(\mathbf{h}, \mathbf{i})$. The solifugid approaches the cricket with the chelicerae open (j). The solifugid measures $25 \mathrm{~mm}$ from the tip of the chelicerae to the end of the abdomen. Time in seconds.
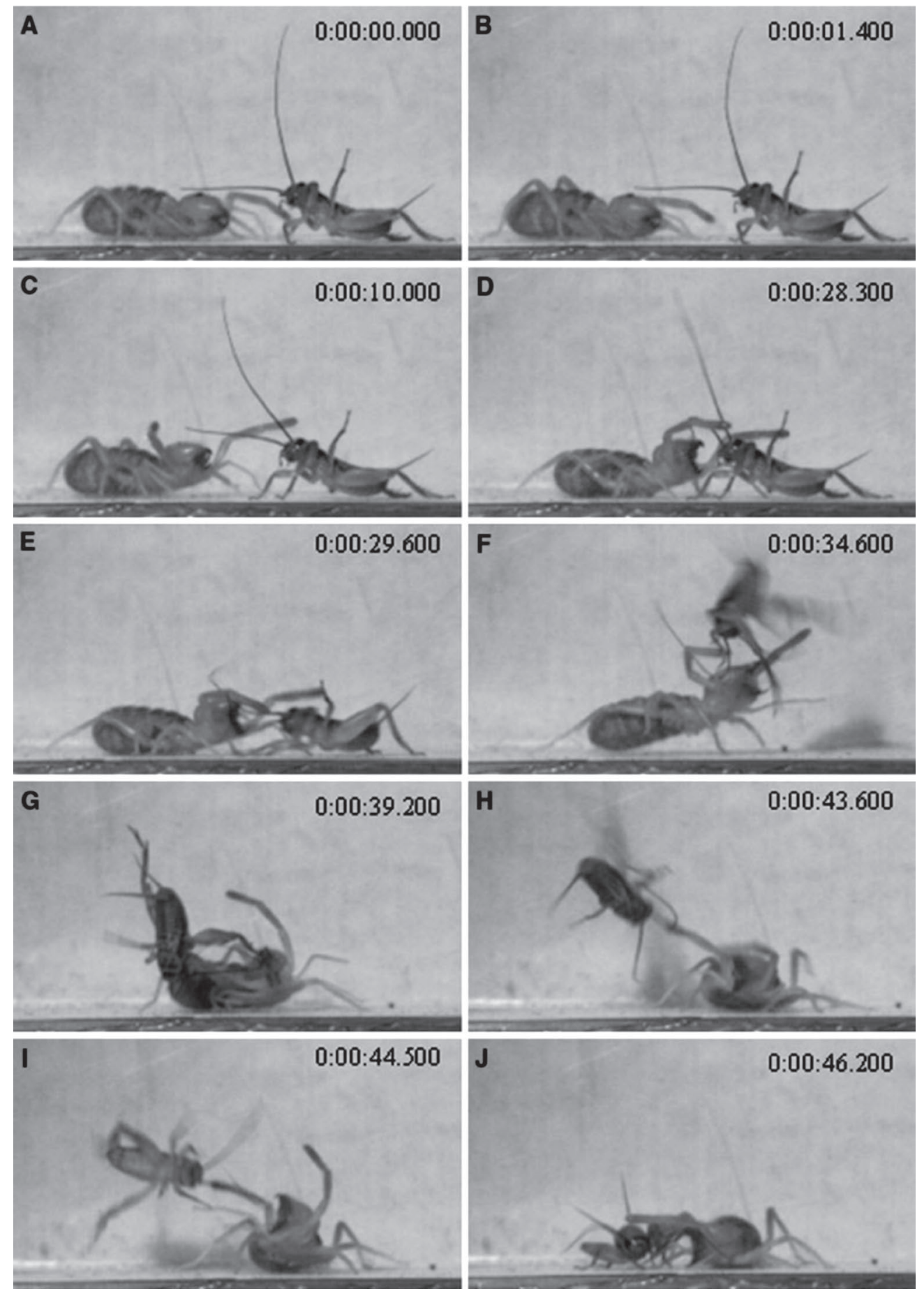

to use adhesion for capturing prey. Interestingly, these are groups that also lack strong spines or pincer-like structures in the pedipalps. The suctorial organs of solifugids, the adhesive seta of spiders, and the glandular setae of harvestmen are located on different body parts and are structurally very different, indicating independent evolutionary pathways.

The suctorial organs of solifugids differ from typical arthropod adhesive organs used in prey capture in two ways - they are not hairy and they do not use gland secretions (Betz and Kölsch 2004; Cushing et al. 2005; Klann et al. 2008). It is interesting to know, therefore, if the adhesive pressures developed by such an atypical organ are comparable to the ones that have evolved in other groups. From our high speed films of prey capture events, we were able to make some tentative calculations on the adhesive pressures that the suctorial organs are able to develop during prey capture. From four 
prey capture sequences in which an airborne jumping cricket's trajectory deviated as a result of adhesion to a solifugid's suctorial organ, we tracked the cricket's position in $x, y$ co-ordinates, obtained the cricket's velocity at each frame, and from that calculated the change in velocity resulting from adhesion to the solifugid's suctorial organ. From this change in velocity, and the cricket's mass, we calculated the force exerted on the cricket through the suctorial organ in each sequence (details of our calculation methodology are provided in the Electronic supplementary material). The maximum adhesive force we calculated $\left(F_{a}\right)$ was $0.026 \mathrm{~N}$, which gave a maximum observed adhesive pressure (force per area of suctorial organ) of $7.3 \times 10^{4} \mathrm{~N} / \mathrm{m}^{2}$ (mean $\pm \mathrm{SD}=4.0 \pm 2.3 \mathrm{~N} / \mathrm{m}^{2}, n=4$ captures, one solifugid, four crickets of varying size). This estimate is within the region of adhesive pressures developed by the adhesive organs of other arthropods - as examples: $2 \times 10^{3} \mathrm{~N} / \mathrm{m}^{2}$ for the bush cricket Tettigonia viridissima (Orthoptera) (Jiao et al. 2000), and $2.24 \times 10^{5} \mathrm{~N} / \mathrm{m}^{2}$ for the jumping spider Evarcha arcuata (Salticidae) (Kesel et al. 2003), and is in excess of that required to support the solifugid's weight during climbing $\left(F_{\mathrm{a}}=0.003 \mathrm{~N}\right.$, adhesive pressure $=9.0 \times 10^{3} \mathrm{~N} / \mathrm{m}^{2}$ ).

In summary, the suctorial organs of solifugids serve an important function as the primary means of capturing fast, mobile prey items. Future study of variation in grasping organs across arachnid groups, and variation in their ecological function, may not only enable an understanding of their evolutionary history, but might one day help in the design of bio-inspired grasping devices.

Acknowledgments - Thanks to P. E. Cushing and J. O. Brookhart for identifying the solifugids, and to R. J. Schilder and S. K. Schwartz for supplying crickets. Figure 1 was kindly provided by Paula E. Cushing, who was supported by National Science Foundation grant DBI-0346378. Two reviewers for Journal of Ethology greatly helped with their suggestions. R.H.W. was supported by Coordenação de Aperfeiçoamento de pessoal de Nível Superior (CAPES).

\section{References}

Beccaloni J (2009) Arachnids. University of California Press, Berkeley, CA

Betz O, Kölsch G (2004) The role of adhesion in prey capture and predator defence in arthropods. Arthropod Struct Dev 33:3-30

Clemente CJ, Federle W (2008) Pushing versus pulling: division of labour between tarsal attachment pads in cockroaches. Proc R Soc Lond B 275:1329-1336

Cushing PE, Brookhart JO, Kleebe H-J, Zito G, Payne P (2005) The suctorial organ of the Solifugae (Arachnida, Solifugae). Arthropod Struct Dev 34:397-406

Gruber J (1970) Die "Nemastoma" - Arten Nordamerikas (Ischyropsalididae, Opiliones, Arachnida). Ann Naturhist Mus Wien 74:129-144

Gruber J (1974) Bemerkungen zur Morphologie und systematischen Stellung von Caddo, Acropsopilio un verwandter Formen (Opiliones, Arachnida). Ann Naturhist Mus Wien $78: 237-259$

Jiao Y, Gorb S, Scherge M (2000) Adhesion measured on the attachment pads of Tettigonia viridissima (Orthoptera, Insecta). J Exp Biol 203:1887-1895

Kesel AB, Martin A, Seidl T (2003) Adhesion measurements on the attachment devices of the jumping spider Evarcha arcuata. J Exp Biol 206:2733-2738

Klann AE, Gromov AV, Cushing PE, Peretti AV, Alberti G (2008) The anatomy and ultrastructure of the suctorial organ of Solifugae (Arachnida). Arthropod Struct Dev 37:3-12

Lee J, Majidi C, Schubert B, Fearing R (2008) Sliding induced adhesion of stiff polymer microfiber arrays: 1 . Macroscale behaviour. J R Soc Interface; doi:10.1098/rsif.2007.1308

Muma MH (1966) Feeding behaviour of North American Solpugida (Arachnida). Fla Entomol 49:199-216

Punzo F (1997) Dispersion, temporal patterns of activity, and the phenology of feeding and mating behaviour in Eremobates palpisetulosus Fitcher (Solifugae, Eremobatidae). Bull Br Arachnol Soc 10:303-307

Punzo F (1998) The biology of camel spiders (Arachnida, Solifugae). Kluwer, Boston, MA

Rovner JS (1980) Morphological and ethological adaptations for prey capture in wolf spiders (Araneae, Lycosidae). J Arachnol 8:201-215

Savory TH (1964) Arachnida. Academic, London

Schubert B, Lee J, Majidi C, Fearing R (2008) Sliding induced adhesion of stiff polymer microfiber arrays: 2 . Microscale behaviour. J R Soc Interface; doi:10.1098/rsif.2007.1309 


\section{Supplementary material}

We filmed a total of 27 prey capture sequences in which solifugids used their suctorial organs to capture crickets. From these, we identified four sequences in which a cricket's jump was resisted by forces exerted by the solifugid's suctorial organ, and which were therefore suitable for further analysis (in all four cases the solifugid was the female). (Note that the example frames in our manuscript did not come from one of these four sequences.) In each case, the solifugid used one suctorial organ to pull an already airborne jumping cricket to the ground.

Our strategy for estimating the suctorial force was to apply Newton's second law to the motion of the cricket. By supplying the change in velocity of the cricket and the time over which this change occurs, and assuming a constant mass for the cricket, the external force applied to the cricket by the suctorial organ can be estimated as follows. Newton's second law states that the acceleration of a point mass is equal to the sum of external forces acting on that body, which for the cricket equates to:

$$
\begin{aligned}
& \sum \vec{F}_{e x t}=m \vec{a} \\
& \vec{F}_{\text {suct }}+m \vec{g}=m \vec{a}
\end{aligned}
$$

Resolving this equation into components (assuming downward is negative $y$ ) gives:

$$
\begin{aligned}
& F_{\text {suct }}^{x}=m a_{x} \\
& -F_{\text {suct }}^{y}-m g=m a_{y}
\end{aligned}
$$

The acceleration of the cricket can be approximated as the change in velocity of the cricket over time, and as such the above can be re-written:

$$
\begin{aligned}
& F_{\text {suct }}^{x}=m \frac{\Delta V_{x}}{\Delta t} \\
& -F_{\text {suct }}^{y}-m g=m \frac{\Delta V_{y}}{\Delta t}
\end{aligned}
$$

The total magnitude of the suctorial force is the vector norm of these components, or

$$
F_{\text {suct }}=\sqrt{\left(m \frac{\Delta V_{x}}{\Delta t}\right)^{2}+\left(m g-m \frac{\Delta V_{y}}{\Delta t}\right)^{2}}
$$

The change in the cricket's velocity, $\Delta V_{x}$ and $\Delta V_{y}$, that occured through application of the suctorial force, was computed as the difference between the velocity of the cricket before and after contact with the suctorial organ. Velocities before and after the contact with the suctorial organ were computed from the change in position of the cricket in subsequent video frames divided by the time between frames, in the video frames immediately before after contact :

$$
\begin{aligned}
& \Delta V_{x}=\left(\frac{\Delta x}{\Delta t_{\text {video frames }}}\right)_{\text {before }}-\left(\frac{\Delta x}{\Delta t_{\text {video frames }}}\right)_{\text {after }} \\
& \Delta V_{y}=\left(\frac{\Delta y}{\Delta t_{\text {video frames }}}\right)_{\text {before }}-\left(\frac{\Delta y}{\Delta t_{\text {video frames }}}\right)_{\text {after }}
\end{aligned}
$$

The cricket's trajectory was digitized by marking the position of its center of gravity, frame-by-frame, using Proanalyst Lite software. This was exported as $x, y$ coordinates, calibrated to distance in millimeters. Inspection of the trajectory of the cricket demonstrated that the force applied by the solifugid on the cricket acted for usually less than one recorded frame $(2 \mathrm{~ms})$, because the trajectory before and after this point was ballistic (parabolic in $y$, and linear in $x$; Figure S1).

The time between video frames of $0.002 \mathrm{~s}$, a cricket mass of $9.08 \times 10^{-5} \mathrm{~kg}$, and a lower bound on the time over which the suctorial force acts $(\Delta t)$ of $0.002 \mathrm{~s}$, coupled with the measured changes in position, were used to compute $F_{\text {suct }}$ using the equations above. The surface area of the everted suctorial organ was measured as $0.35 \mathrm{~mm}^{2}$ (Using a SpotFlex 64MP digital camera mounted on a standard dissecting microscope....). Using this, observed adhesive pressure was calculated $\left(F_{\text {suct }} /\right.$ area; force per $\mathrm{m}^{2}=$ Pascals). The maximum calculated value for $F_{\text {suct }}$ was $0.026 \mathrm{~N}$, giving maximum adhesive pressure of $7.3 \times 10^{4} \mathrm{~N} / \mathrm{m}^{2}$.

Next we estimated the forces resisted by the suctorial organ during climbing of smooth surfaces. During such climbing, the pedipalps alone are used and the walking legs do not participate (Cushing et al. 2005). Thus, the forces resisted by a single suctorial organ during climbing will be on the order of the solifugid's body weight. The female solifugid had a mass of $3.38 \times 10^{-4} \mathrm{~kg}$. Using $F=m g$, the estimated force resisted by the suctorial organ in climbing will be $0.003 \mathrm{~N}$, or $9.0 \times 10^{3} \mathrm{~N} / \mathrm{m}^{2}$. 

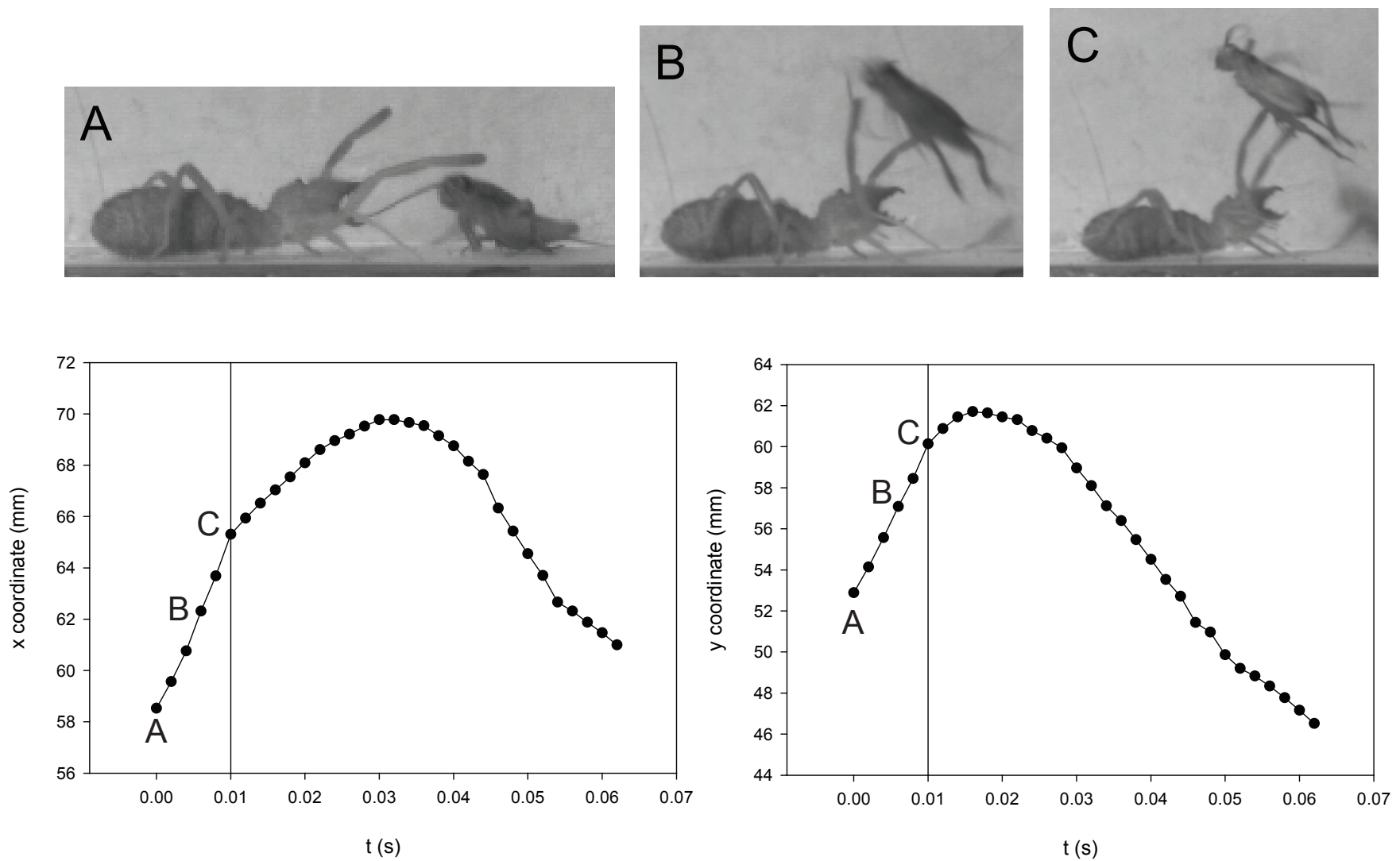

Figure S1 : $x$ and $y$ co-ordinates of a cricket's jump trajectory over time. At the start of the jump, the cricket is unopposed by the solifugid's suctorial organ which attaches after the cricket is airborne in this example. The suctorial organ attaches, and exerts force on the cricket's trajectory at the point indicated by the vertical solid line. Following this impulse of force, the cricket travels along a modified trajectory. This figure and all calculations were made from a capture distinct from the one presented in the paper. $\mathrm{A}=$ the cricket jumps; $\mathrm{B}=$ the cricket is airborne but still did not touch the pedipalp; $\mathrm{C}=$ the suctorial organ makes contact with the cricket. 